\title{
Primary detection of congenital heart diseases in the Kyrgyz Republic
}

Irina A. Akhmedova, Gulzada A. Imanalieva, Damir A.Abibillaev, Taalaibek Z. Kudaiberdiev

Scientific Research Institute of Heart Surgery and Organ Transplantation, Bishkek, Kyrgyzstan

\section{Abstract}

Objective: The aim of this paper is to understand the structure of congenital heart diseases (CHD) and the age of the first diagnosis in a population referred to specialized cardiac surgery center from different regions of Kyrgyz Republic.

Methods: In 2017, 7213 people of different ages, from Kyrgyz Republic were examined by using transthoracic echocardiogram at cardiac surgery center aimed to detection of congenital heart disease

Results: In total, 478 new patients with primary diagnosis of CHD were identified; 413 (86\%) patients had a delayed diagnosis. The total detectability was $6.75 \%$. The structure of congenital heart disease has a large difference depending on the age group. The proportion of complex heart defects predominates in newborn children and significantly decreases with age.

Conclusion: A study of the prevalence and structure of heart defects in the country will help to find the right decision in planned care for patients with CHD, in cases of limited resources.

Keywords: newborn, congenital heart defects, diagnostics, prevalence, echocardiography

(Heart Vessels and Transplantation 2018: 2: doi: 10.24969/hvt.2018.66)

\section{Introduction}

Congenital heart defect (CHD) - defined by Mitchell et al., as "A gross structural abnormality of the heart or intrathoracic vessels" (1), is one of the most frequent congenital anomalies and takes the third place in the prevalence among congenital malformations in the world, second only to the developmental defects of the neural tube and musculoskeletal system. It is also one of the main causes of infant mortality in the world (2). Every year the number of patients with CHD is steadily increasing. According to the World Health Organization (WHO), 1.35 million newborns with CHD are born annually (3). With the provision of timely cardiac care, more patients reach maturity and create new patients patients with adult congenital heart disease, with prevalence of 4 per 1000 adults (3). Such data are not available in developing countries, but are likely to be lower due to the lack of early qualified cardiac and cardiac surgery care (4). The structure of the CHD and its prevalence depend primarily on the diagnostic method used in the study and the age at which the study was conducted. When examining newborn children by echocardiography, small defects of the interventricular and interatrial septum predominate, small sizes of the open arterial duct, when all forms of $\mathrm{CHD}$ are included, the prevalence of $\mathrm{CHD}$, according to Julien et al. (6) can reach up to 75 cases per 1000 live newborns. Moderately severe CHD is observed in 6 per 1000 newborns (5). In older children and adults, CHD is characterized by predominance of atrial septal defect (ASD), small ventricular septal defect (VSD), moderate pulmonary artery stenosis (PS), truncus arteriosis (TA), and bicuspid aortic valve. The growth and development of cardio-surgical care at present in this category of patients allows correction of severe forms of CHD in the neonatal period with a reduction in mortality in this age group by $77 \%$ (6). Early detection of CHD and timely cardiac surgery is extremely important for prognosis in children with heart defects. The total mortality from $\mathrm{CHD}$ in natural course is high enough. As a rule, in most low- and middle-income countries, the diagnosis of $\mathrm{CHD}$ occurs with a significant delay (7).

Address for Correspondence: Taalaibek Z. Kudaiberdiev, SRI of Heart Surgery and Organ Transplantation, Togolok Moldo Str 3/1, Bishkek, Kyrgyzstan. Email: tkudaiberdiev@gmail.com 
The average age of the diagnosis can range from the first day of life to almost 80 years (10). Even in countries with a high level of cardiosurgical care, there is a delay in establishing a diagnosis at birth in $8.9 \%$ of cases (8). At the same time, in the context of a shortage of resources, in low-income countries, the management of the CHD emphasizes the treatment of "curable" heart defects, and "favorable" cases, which were "naturally chosen." $(9,10)$

In this study, we sought to study the structure of newly diagnosed CHD and the age of the diagnosis within Kyrgyz Republic.

\section{Methods}

The study was conducted in 2017, at the Scientific Research Institute of Heart Surgery and Organ Transplantation in Bishkek, Kyrgyz Republic. The study was conducted among the patients that came from different regions in the country who applied to the clinic with goal of receiving primary care at their place of residence or independently if complaints were present. A total of 7,213 people were examined. The examination was carried out using transthoracic 2dimensional Doppler echocardiography by all authors, participated also in diagnostic procedures. Patients of all ages were included in the study, with the initial diagnosis of various forms of CHD. Patients with congenital rhythm disturbances, cardiomyopathy, myocarditis, and acquired valvular heart disease were excluded.

\section{Results}

Among 7,213 people referred to the center, 478 new patients with a primary diagnosis of $\mathrm{CHD}$ were identified. The total detectability of CHD was $6.75 \%$. Of these, 216 (45.18\%) were male and 262 (54.81\%) were female. Only in 65 children a diagnosis was made before discharge from the maternity hospital, 413 (86\%) patients had a delayed diagnosis.

All patients were divided into 4 age groups: Group 1 newborns 0-28 days, Group 2 - children of early age between 1 month and 1 year, Group 3 - children and adolescents - between 1 year and 16 years, Group 4 adults over 16 years.

Primary detection depending on the age group was distributed as follows: 597 newborns were surveyed in the first group, 144 CHD were detected, and $24.12 \%$ were detectable. In the second group, 1902 children were examined, 170 patients with CHD were detected, and detectability was $8.93 \%$. In the third group, 2,712 people were examined, 102 patients with CHD were identified, with a detectability of $3.76 \%$. In the fourth group, 2002 were examined, 62 patients with CHD were identified, and the detectability was $3.09 \%$, respectively (Table 1).

\begin{tabular}{|l|c|c|c|c|}
\hline \multicolumn{4}{|l|}{ Table 1. Identification of CHD } \\
\hline & $\begin{array}{c}\text { Group 1 } \\
(\mathbf{n = 1 4 4 )}\end{array}$ & $\begin{array}{c}\text { Group 2 } \\
(\mathbf{n = 1 7 0 )}\end{array}$ & $\begin{array}{c}\text { Group 3 } \\
(\mathbf{n = 1 0 2})\end{array}$ & $\begin{array}{c}\text { Group 4 } \\
\text { (n=62) }\end{array}$ \\
\hline Examined, $\mathrm{n}$ & 597 & 1902 & 2712 & 2002 \\
\hline CHD detected, $\mathrm{n}$ & 144 & 170 & 102 & 62 \\
\hline Detectability, \% & 24.12 & 8.93 & 3.76 & 3.09 \\
\hline \multicolumn{4}{|l|}{ CHD - congenital heart disease }
\end{tabular}

The structure of CHD is significantly different depending on the age groups (Table 2). The first group included 144 patients aged 0 to 28 days. Cyanotic defects amounted to 38 (26.38\%), acyanotic defects 106 (73.61\%). The structure of CHD among cyanotic disease: tetralogy of Fallot (TOF) -13 (34.21\%), double outlet right ventricle (DORV) with pulmonary artery stenosis (PS) -10 (26.31\%), transposition of great vessels (TGA) 6 (15.78\%), total truncus arteriosus - 3 (7.89\%), total anomalous pulmonary veins drainage (TAPVC) - 3 (7.89\%), pulmonary atresia $-2(5.26 \%)$, hypoplasia of the left ventricle and left atrium - 1 (2.63\%). The structure of the CHD among the acyanotic defects: patent ductus arteriosus (PDA) - 51 (48.11\%), ventricular septal defect (VSD) - 35 (33.01\%), atrial septal defect (ASD) - 15 $(14.15 \%)$, atrioventricular septal defect (AVSD) - 2 (1.88\%), other - $3(2.83 \%)$. 
The second group included 170 patients aged 1 to 12 months. Cyanotic defects were documented in 25 (14.7\%), acyanotic defects - 145 (85.3\%). The structure of CHD among cyanotic vices: TOF - 12 (48\%), DORV with PS- $3(12 \%)$, TAPVC - 7 (28\%), tricuspid valve atresia - $3(12 \%)$. The structure of the CHD among the acyanotic defects: PDA - 22 (15.17\%), VSD - 56 (38.62\%), ASD - 34 (23.44\%), AVSD - 4 (2.75), mild PS - 8 (5.51\%), and other - 21 (14.48\%).

The third group included 102 patients aged 1 year - 16 years. Cyanotic defects - 8 (7.84\%), acyanotic defects 94 (92.15\%). The structure of CHD among cyanotic vices: TOF - 6 (75\%), DORV 1 (12.5\%), single ventricle $1(12.50 \%)$. The structure of CHD among the acyanotic defects: PDA - 12 (12.76\%), VSD - 37 (39.36\%), ASD - 25 (26.59\%), AVSD - 3 (3.19\%), mild PS - 9 (9.57\%), coarctation of the aorta - $3(3.19 \%)$, bicuspid aortic valve $-5(5.31 \%)$.
The fourth group included 62 patients over the age of 16 years. The oldest patient with ASD at the time of diagnosis was 77 years old. Cyanotic defects are documented in 2 (3.22\%), acyanotic defects - 60 (96.77\%). The structure of CHD among cyanotic defects are: TOF-1 (50\%), severe PS- $1(50 \%)$. The structure of CHD among the acyanotic defects: PDA - 7 (11.66\%), VSD - 8 (13.33\%), ASD - 27 (45.00), AVSD - 2 (3.33\%), mild PS - 2 (3.33\%), coarctation of the aorta - 2 (3.33\%), bicuspid aortic valve - $8(13.33 \%)$, Ebstein's anomaly - 3 (5\%), VSD + PDA 1 (1.66\%). Patients with cyanotic defects were admitted to the clinic in a critical condition.

In six female patients, the primary diagnosis (in all ASD) was performed with a planned examination during pregnancy at the gestational age of more than 26 weeks.

\begin{tabular}{|c|c|c|c|c|}
\hline Type of congenital heart disease & $\begin{array}{l}\text { Group } 1 \\
(n=144)\end{array}$ & $\begin{array}{l}\text { Group } 2 \\
(n=170)\end{array}$ & $\begin{array}{l}\text { Group } 3 \\
(n=102)\end{array}$ & $\begin{array}{c}\text { Group } 4 \\
(n=62)\end{array}$ \\
\hline $\begin{array}{l}\text { Cyanotic CHD, } n \\
\text { TOF, } n(\%) \\
\text { DORV with PS, } n(\%) \\
\text { DORV, } n(\%) \\
\text { TGA, } n(\%) \\
\text { TA, } n(\%) \\
\text { TAPVC, } n(\%) \\
\text { Pulmonary atresia, } n(\%) \\
\text { Tricuspid valve atresia, } n(\%) \\
\text { PS (severe) , } n(\%) \\
\text { Hypoplasia of left heart, } n(\%) \\
\text { Single ventricle, } n(\%)\end{array}$ & $\begin{array}{c}38 \\
13(34.21) \\
10(26.31) \\
- \\
6(15.78) \\
3(7.89) \\
3(7.89) \\
2(5.26) \\
- \\
- \\
1(2.63) \\
- \\
\end{array}$ & $\begin{array}{c}25 \\
12(48) \\
3(12) \\
- \\
- \\
- \\
7(28) \\
- \\
3(12) \\
- \\
- \\
- \\
\end{array}$ & $\begin{array}{c}8 \\
6(75) \\
- \\
1(12.5) \\
- \\
- \\
- \\
- \\
- \\
- \\
- \\
1(12.5)\end{array}$ & $\begin{array}{c}2 \\
1(50.00) \\
- \\
- \\
- \\
- \\
- \\
1(50.00) \\
-\end{array}$ \\
\hline $\begin{array}{l}\text { Acyanotic CHD, } n \\
\text { ASD, } n(\%) \\
\text { VSD, } n(\%) \\
\text { PDA, } n(\%) \\
\text { Ebstein Anomaly (mild) , } n(\%) \\
\text { PS (mild) , } n(\%) \\
\text { AVSD, } n(\%) \\
\text { Coarctation of the aorta, } n(\%) \\
\text { VSD+PDA, } n(\%) \\
\text { Bicuspid aortic valve, } n(\%) \\
\text { Other, } n(\%)\end{array}$ & $\begin{array}{c}106 \\
15(14.15) \\
35(33.01) \\
51(48.11) \\
- \\
- \\
2(1.88) \\
- \\
- \\
- \\
3(2.83)\end{array}$ & $\begin{array}{c}145 \\
34(23.44) \\
56(38.62) \\
22(15.17) \\
- \\
8(5.51) \\
4(2.75) \\
- \\
- \\
- \\
21(14.48)\end{array}$ & $\begin{array}{c}94 \\
25(26.97) \\
37(39.36) \\
12(12.76) \\
- \\
9(9.57) \\
3(3.19) \\
3(3.19) \\
- \\
5(5.31) \\
-\end{array}$ & $\begin{array}{c}60 \\
27(45.00) \\
8(13.33) \\
7(11.66) \\
3(5.00) \\
2(3.33) \\
2(3.33) \\
2(3.33) \\
1(1.66) \\
8(13.33) \\
-\end{array}$ \\
\hline
\end{tabular}




\section{Discussion}

There was no significant difference in gender between groups. The structure of the CHD is diverse for different age groups and there was no enough sample to determine the prevailing nosology for this region, especially in newborns and young children, given the short period of time and the small amount of material. In the first group of patients, PDA, VSD, ASD and their combination predominate, which is associated with the routine referral by pediatricians all newborns with insignificant heart murmurs for echocardiography. Similarly, in newborns, a greater percentage of diagnostics were of complex and critical CHD, which needed urgent surgical correction of the defect. We attribute this to the fact that newborns born in the capital and nearby regions of the country are often sent for examination. The proportion of detecting cyanotic defects with age is significantly reduced, which also correlates with the data that more than half of the children born with CHD do not survive the first year. And in the older groups, mild and moderate forms of CHD predominate.

Kyrgyzstan, according to the World Bank, is one of the countries with income below the average (12). The rate of live births for 2017, according to the National Statistics Committee, was 158 out of 160 newborns (11). Applying the median prevalence of CHD 8 per 1,000 live births, we must diagnose newborns with $\mathrm{CHD}$ in 1265 , but we diagnosed only in 144 , and then only the small defects and small anomalies of development of heart. In remote areas of the country, diagnosis is difficult and is not carried out due to the lack of qualified medical personnel. Annually we have less than 1000 newborns with CHD, hence the high percentage of heart defects in older age groups and in the adult population. Children are sent to the cardiac surgery center already at an older age and with serious complications present. For the population of 6.1402 million people in the country there is one head institution rendering specialized cardio-surgical assistance to patients located in the capital, Bishkek. When all CHD patients are identified or are suspected of having CHD, all patients are referred to the center.
The prenatal screening program is available only in the central cities of the country, and its effectiveness is not high. Most of the rural population, due to the special mountainous terrain, does not have access to qualified medical care. In 2014, the staff of the center introduced a scientific program on the fetal diagnosis of CHD in practice, with an emphasis on women with a history of CHD (operated or not). However, in practice, it was not properly used, so in 2017, under this program, only 17 pregnant women were examined, without the diagnosis of CHD in the fetus.

The definition of the structure and prevalence of CHD on the territory of the country is the first point in determining the true extent of the problem and will help to find the right decision in planning care for patients with CHD under conditions of limited resources. Having studied it, we will determine the true contribution of the CHD to the structure of infant mortality, since in the republic, at the present time, in connection with religious and national traditions, postmortem diagnosis of the causes of lethality is not always carried out.

\section{Study limitations}

Relatively small sample size is the main limitation of the study, which included only population referred to the center for examination, further studies are needed to define prevalence of CHD in country.

\section{Conclusions}

The main problem of the country's health system is the lack of systemic care for patients with CHD. To solve it, you need to:

1. Implement a national program for the prevention and early diagnosis of CHD.

2. Establish programs to train medical personnel focusing on early detection of CHD.

3. Involve the interest of state and non-governmental organizations in the provision of programs for the early detection of CHD.

4. Work directly with the population from different regions of the country 
Peer-review: External

Conflict of interest: None to declare

Authorship: I.A.A., G.A.I., D.A.A., and T.Z.K. equally contributed to the study and preparation of manuscript and fulfilled all authorship criteria

Acknowledgement and funding: None to declare

\section{References}

1. Mitchell SB, Korones HW. Berendes. Congenital heart disease in 56,109 births. Incidence and natural history. Circulation 1971; 43: 323-32.

2. Bjornard K, Riehle-Colarusso T, Gilboa SM, Correa F. Patterns in the prevalence of congenital heart defects, metropolitan Atlanta, 1978 to 2005. Birth Defects Res A Clin Mol Teratol 2013; 97: 87-94.

3. der Linde D, Konings EM, Slager MA, Wisenburg M. Birth prevalence of congenital heart disease wordwide: a systematic review and meta - analysis. J Am Coll Cardiol 2011; 58: 2241-7.

4. Saxena A. Adult with heart disease in developing country: scope, challenges and possible solutions. Curr Treat Options Cardiovasc Med 2015; 17: 46.
5. Hoffman JIE, Kaplan S. The incidence of congenital heart disease. J Am Coll Cardiol 2002; 39: 1890-900.

6. Khairy $P$, lonescu-Ittu R, Mackie AS, Abrahamowicz $\mathrm{M}$, Pilote $\mathrm{L}$, Marelli AJ. Changing mortality in congenital heart disease. J Am Coll Cardiol 2010; 56: 1149-57.

7.Rashid U, Qureshi AU, Hyder SN, Sadiq M. Pattern of congenital heart disease in a developing country tertiary care center: Factors associated with delayed diagnosis. Ann Pediatr Cardiol 2016; 9: 210-5.

8. Massin MM, Dessy $H$. Delayed recognition of congenital heart disease. Postgrad Med J 2006; 82: 46870.

9. Mocumbi AO, Lameira E, Yaksh A, Paul L, Ferreira MB, Sidi $D$. Challenges on the management of congenital heart disease in developing countries. Int J Cardiol 2011; 148: 285-8.

10. Bode-Thomas F. Challenges in the management of congenital heart disease in developing countries. January 2012 with 107 Reads. DOI: 10.5772/27273. Source: InTech. In book: Congenital Heart Disease Selected Aspects.

11.National Statistical Committee of Kyrgyz Republic. Available at: URL: www.http://stat.kg.

12.World Bank. Available at: URL: www.worldbank.org 